\section{The Change: Women, Ageing and the \\ Menopause}

\section{Germaine Greer}

Hamish Hamilton: London 1991, £16.99, ISBN $0241128404 \mathrm{Hbk}$

Germaine Greer's newest book on menopause is as difficult to chart, as uneven, unpredictable and fascinating as the subject itself. She refers to the menopause as a taboo subject, a misunderstood 'time of life' needing exploration, demystification and redefinition. Quite rightly she lays bare the medical profession's lack of any coherent understanding or knowledge of the physiology or psychology of 'the change'. She explains, in great detail, what is known of the physiological developments which happen during the varied number of years each individual woman goes through it. She explores the relationship between the use of hormone replacement therapy (HRT) and fear of ageing (changing). Many feminists, old and new, are now approaching or have gone through 'the change'. We're experiencing what Greer is exploring; it addresses us, or those who can imagine its onset. That goes a long way in explaining why reactions to the book are so varied and strong. What younger women make of it is not important to Greer.

However, and somewhat contradictorily (but when isn't she contradictory?), Greer has stated that she didn't write this book for a target audience or for anyone in particular. She is not, she says, a feminist spokeswoman. It is her strength and weakness that she almost always writes out of her own experience, going on to construct huge generalizations and peppering the work with bits and bobs from anthropology, literature, medicine and psychology. Because she is an interesting, provocative writer she gets away with a heady mix of murder, mayhem and profundity, all delivered in the full blaze of public fascination.
Greer believes that the notion of 'no change' at menopause serves the continuation of women's subjugation to men. She sees the climacteric as being composed of three periods, "two that exist and one that does not; the first is the peri-menopause, the time leading up to and the last bleed, the second is the menopause proper, the bleed that does not come, and the third is the post menopause. The critical time corresponds with the fifth climacter of a woman's life, the fifth of her seven ages.'

Does she or doesn't she believe in biological destiny for women? She posits motherhood as the most naturally achieved, naturally powerful position for women to hold in society, so it seems the answer is yes. In the chapter entitled 'The Lucky Ones' Greer describes 'traditional' societies in which mothers and grandmothers have defined and powerful roles to play, and in relation to these romanticized anthropological tidbits says, 'We can only wonder how much less women might suffer at menopause if they were to acquire power, prestige and responsibility instead of losing all three.' Yes, but why should this most 'naturally' happen via motherhood and a powerful role in the family sphere?

Speaking of possibilities for older women, Greer states that, 'We might develop better strategies for the management of the difficult transition if we think of what we are doing not as denial of the change or postponement of the change, but as acceleration of the change, the change back into the self you were before you became a tool of your sexual and reproductive destiny.'

Basically The Change represents a romanticized version of traditional societies in which women had an honoured and powerful place via motherhood and where the menopause did not signal loss of the double-edged methods women in 'modern' societies have developed to cope with their biological and sexual 
destinies. These modern women, Greer says, have only the sexual attractiveness of youth, or relationships with their husband or employer, and because the state has taken over the socialization of children, they have no meaningful mothering role except drudgery. However, Greer states, it's no wonder, that Western, 'modern' women resist the menopause, because the nature of the change is almost always perceived as loss, deficiency, invisibility, even if the reality is a sham.

In contrast, Greer suggests a radical shake-up in our perception of old age and the change. 'The change hurts. Like a person newly released from leg-irons, the freed woman staggers at first. Though her excessive visibility was anguish, her present invisibility is disorienting'. Greer scalpels Simone de Beauvoir's attitude to old age in one of the book's most interesting analyses of famous older women: 'Every day she told herself, "I am not what I was" and wasted precious time in bitter regret.'

What Greer gives us is a picture of women bowed down by their husbands' sexual demands, receiving attention only because of their youthful sexual attractiveness, with possibility for meaningful relationships restricted to the husband or the employer, under the sway of an ill-defined biological destiny. And then, up pops the change, another biological imperative, which in itself 'should' signal possibilities of freedom from the 'leg-irons'. The loss of sexual attractiveness to men 'should' mean freedom from sexual demands, it 'should' signal the possibility of sombre independence, of meeting one's own needs, not the powerless servicing of others' needs. 'In modern nuclear families there is only one relationship of intimacy and importance and that is the relationship between spouses. If that does not work the family must be jettisoned. The modern woman has only two possible sources of satisfaction, her relationship with her husband and her relationship with her employer.' But older modern women are not, because of sexism and ageism, able to see the positive side of the menopause. 'She has a choice, to become the kind of stentorian bully who can be heard apostrophizing saleswomen from the other side of the store, or to fade out of sight and hearing.'

It would be silly to refute totally the dreary, depressing, put-upon picture Greer paints of women's lives in our society; however, it is profoundly depressing that Greer has chosen to ignore the impact of feminism on women, and to an extent, men, in our 'modern' societies. Friendship between women at any stage of their lives is almost absent in the Greer scenario. Friendships forged through feminism, friendships developed in neighbourhoods, through motherhood, through work, or in lesbian cultures, have no place of pride in the female guide to surviving well in a sexist and ageist society.

And what about lesbianism? No, not every book, on any subject, has to include lesbians. (Although an awareness and acknowledgement of assumed heterosexuality would be welcome.) However, in a book which includes a chapter on hardy perennials (this one got all the publicity because of its cutting remarks about well-known celebrities, although, since women like Joan Collins and Jane Fonda have put themselves in the limelight as role models for older women, taking them down a peg or two seems fair enough to me), as well as ones on the aged wife, the lucky ones, etc., the absence of lesbians is glaring. Lesbians go through the change, lesbians are not in sexual relationships with men. Wouldn't it have been interesting to ask whether or not the changes most of them have made before their menopause, but within a sexist and ageist society, have had any impact on how they see themselves - in the world and sexually?

But Greer embraces the end of 
sexual relationships and because this is based entirely within a heterosexual framework, any exploration outside of that framework would make her arguments messy. The older, heterosexual menopausal woman who really has sexual urges (a minority, she argues, if women are honest about it) is unfortunately the plaything of her particular hormonal imbalance, and may be subject to 'humiliating bouts' of masturbation. Unless she is still submitting to her husband's demands for sex (and most men will have gone off her physically ageing body anyway) she will welcome the end of sex. Not for her images of the happy crone with her vibrator. Feminists have gone on forever about the negative aspects of women submitting to unwanted sex; this is important. However, Greer throws all sexual expression down the plughole, as if sexual needs or desires were primarily hormonal, ignoring all the complex components of desire, pleasure and intimacy. Some women will find the menopause a welcome release from an unwelcome sexual availability, but why should they wait until the menopause?

Greer says, 'The most heartening thing that writers can find to say about the menopause is that there need be "no change", as if human life was anything but change.' Most $F R$ readers, including myself, will concur wholeheartedly. But why, oh why, should the menopause be the point at which women are freed from the 'leg-irons'? Yes, it is one significant point in most women's lives; it is also, for most of us, feminist or not, a too little discussed, ambivalent, change. But the ambivalences of childhood and growing up, sexuality, child care and motherhood, work relationships, partnerships with men (and women), body image and the cultural imperatives of femininity, are rich ground for making profound changes too. We want the 'potency' Greer refers to, to begin well before 'the change'.

Greer has brought the menopause into public discourse, and for that I'm thankful. She has posed hundreds of questions which need exploration and answers. Her own views make compelling reading, but they cannot stand as the 'comprehensive study' her publishers claim they are. We need more, different, and feminist work done on the subject.

\section{Sue O'Sullivan}

\section{Invisibility Blues: From Pop to Theory} Michelle Wallace

Verso: London 1990, ISBN 0860915190 $£ 9.95$ Pbk, ISBN $0860913015 £ 29.95$ $\mathrm{Hbk}$

The trouble with collections of essays lies in the form's inability to develop an argument throughout the work since frequently pieces seem to be selected on the basis of their potential for immediate appeal rather than for their development of a particular argument. There are times when I long for a complete book on a particular subject where questions are raised and addressed - not, of course, necessarily answered - and where issues are examined in more depth.

This collection of Michelle Wallace's essays, although it contains some powerfully written articles and indicates some of Wallace's personal development over the last eighteen years or so, at times lacks a sense of wholeness. It is divided into four sections covering Black Feminism and Autobiography; Pop; Culture and History; and Theory. The essays span Michelle Wallace's entire career as a writer and cultural critic but this collection tantalizingly approaches issues and sketches out questions but does not finally, adequately analyse the problems raised by her critical work. 